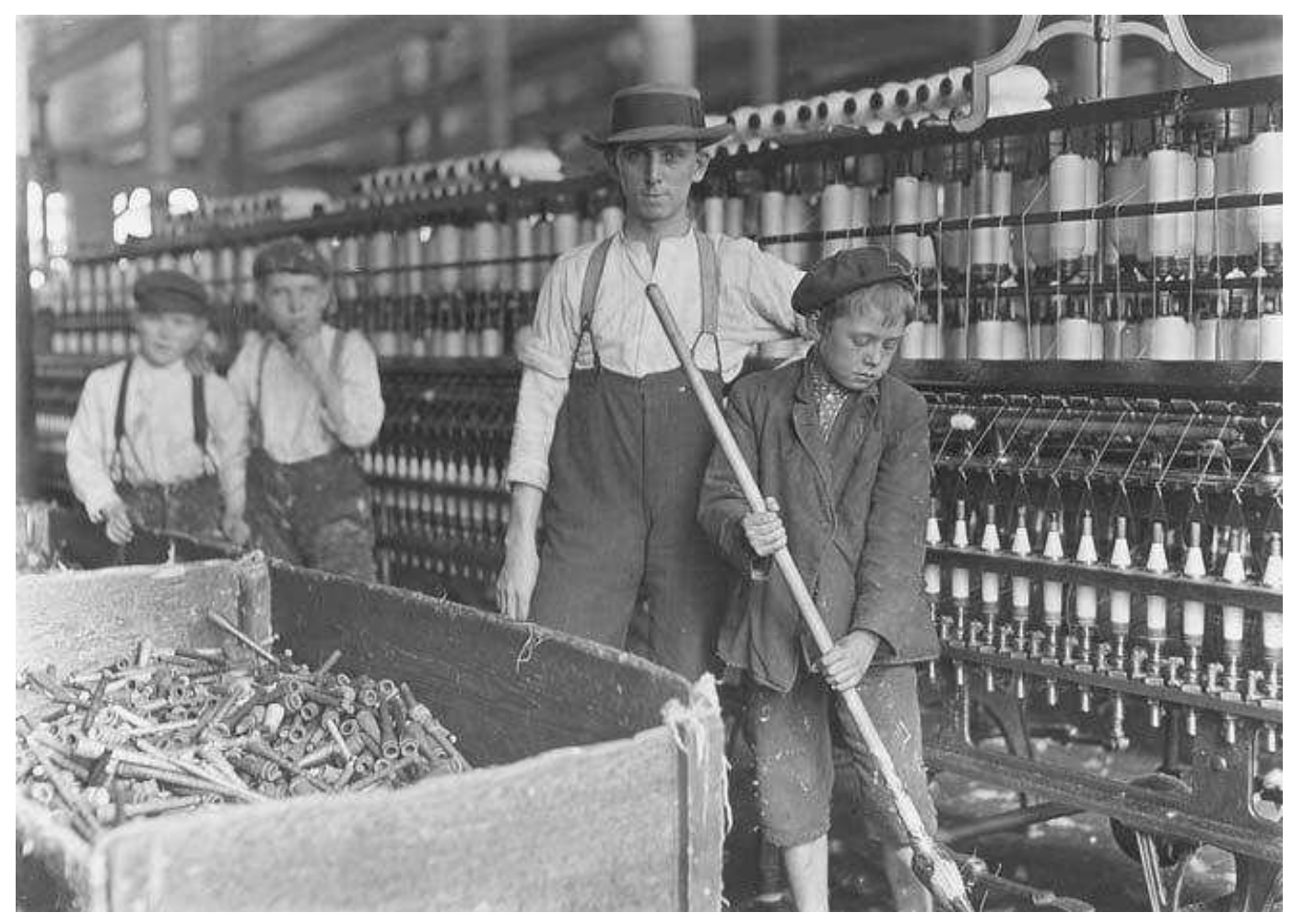

Lewis Hine (1874-1940), Lancaster, NC, EUA. 


\title{
Repercussões das metamorfoses no mercado de trabalho do Serviço Social brasileiro
}

\author{
Repercussions the metamorphoses in the labor market \\ of Brazilian Social Work
}

Maria Augusta da Silva Tavares*

\begin{abstract}
Resumo: Neste artigo busca-se discutir as repercussões das metamorfoses no mercado de trabalho do Serviço Social brasileiro. O objetivo central foi o de analisar as alterações no mercado de trabalho considerando o atual estágio do capitalismo. Entretanto, o texto apresenta um breve histórico das (re)configurações neste mercado de trabalho considerando os acontecimentos sociopolíticos e econômicos que contribuíram para suas metamorfoses ao longo da trajetória do Serviço Social.
\end{abstract}

Palavras-chave: trabalho; mercado de trabalho; Serviço Social.

\begin{abstract}
This article will discuss the repercussions of metamorphoses in the labor market of the Brazilian social work. The main objective is to analyze the changes in the labor market given the current stage of capitalism. The text presents a brief history of the (re) configuration in this labor market considering the socio-political and economic events that contributed to their metamorphoses throughout the trajectory of social work.
\end{abstract}

Keywords: labor; labor market; social work.

\footnotetext{
* Assistente Social, mestre e doutoranda pelo Programa de Pós-Graduação em Serviço Social da Universidade Estadual do Rio de Janeiro (PPGSS/UERJ); Bolsista de Apoio Técnico do Programa de Estudos do Trabalho e Reprodução Social (PETRES/UERJ). Correspondência: Programa de Estudos do Trabalho e Reprodução Social (PETRES/UERJ). Rua São Francisco Xavier, n. 524, Bloco "E", Sala 8025 - Maracanã, CEP: 20550-013. Rio de Janeiro - E-mail: <guta_ tavares@yahoo.com.br>.
} 


\section{Introdução}

O presente artigo propõe uma reflexão acerca das repercussões das metamorfoses no mercado de trabalho do Serviço Social brasileiro. Ressalta-se que as tendências contemporâneas no mercado de trabalho do Serviço Social brasileiro devem ser analisadas considerando o atual estágio do capitalismo na medida em que este impõe significativas redefinições ao Serviço Social, como nas demais profissões, sobretudo nas condições de trabalho e pela redefinição da sua demanda sócio-histórica, que implica em mudanças no seu significado e funcionalidade social.

Os processos globais de alteração no modelo de produção e reprodução das relações sociais no atual estágio do capitalismo, estabeleceram novas condições para o trabalho, aprofundando a "desvalorização e a superexploração da força de trabalho" para garantir "a continuidade da reprodução ampliada do capital" (ALENCAR; GRANEMANN, 2009, p. 162). Tais processos foram desencadeados com maior expressão a partir da crise estrutural do capital nos anos 1970, e como resposta, iniciou-se a reorganização econômica, política e ideológica de dominação, cujos reflexos mais visíveis recaem sobre o trabalho organizado.

Dentre as principais consequências, situam-se as alterações no processo produtivo, agora caracterizado pelas flexibilização e descentralização da produção em que a terceirização assume grandes proporções. Nesse cenário, são reeditadas formas pretéritas de trabalho, como, por exemplo, o trabalho por peça e domiciliar, além do predomínio de regimes de trabalho em contrato temporário e jornada de tra-balho parcial. Embora as reestruturações econômicas e políticas com impactos no trabalho sejam próprias da dinâmica do capital, não sendo, portanto, novidade histórica, há que se considerar as condições nefastas que atualmente conferem para a força de trabalho (ALENCAR; GRANEMANN, 2009, p. 162).

A temática é abordada por meio de uma pesquisa bibliográfica baseada na exposição da literatura já publicada, principalmente, em forma de livros, dissertações e revistas eletrônicas. O estudo busca construir um diálogo entre os autores que abraçam a teoria crítica como um caminho teórico-metodológico capaz de desvendar as relações entre a profissão e a dinâmica social. Neste sentido, as argumentações teóricas recorrem à história da profissão, com ênfase aos acontecimentos sociopolíticos que conformam as particularidades deste mercado profissional de trabalho no Brasil.

A condição prévia para a exposição histórica sobre o Serviço Social é a de afirmar a profissão como um tipo de especialização do trabalho 
na sociedade capitalista. Esta reflexão, juntamente com tantas outras, é fruto do amadurecimento intelectual da categoria profissional que se firmou nos anos 1980, durante o "processo de renovação do Serviço Social" (NETTO, 2004).

Ao revelar o Serviço Social como trabalho inscrito no âmbito da produção e reprodução da vida em sociedade, entende-se que este mercado de trabalho se materializa dentro da estruturação de ordem capitalista, caracterizada pelo conflito das classes em disputa que define o poder sobre o mercado. Portanto, assume controle e domínio sobre o mesmo, a classe que detém os meios e condições de produção. Não dispondo dos meios e condições necessárias à efetivação de seu trabalho, o trabalhador necessita vender a sua força de trabalho para a sobrevivência, sofrendo todas as oscilações presentes no mercado, sobretudo a partir das novas formas de organização e de gestão do trabalho, em consequência das transformações econômicas e sociopolíticas nos processos de acumulação do capital nos últimos anos.

Toma-se como referência para elaboração deste artigo, estudos e pesquisas presentes na literatura do Serviço Social que problematizam os seus fundamentos e sua emergência no Brasil (IAMAMOTO, 1992; IAMAMOTO; CARVALHO, 2000; NETTO, 2011) estendendo-se até o período do Movimento de Reconceituação, com ênfase às (re)configurações do mercado de trabalho (IAMAMOTO, 2001; NETTO, 2004). Em seguida, refletese sobre o atual cenário e as tendências no mercado de trabalho do Serviço Social brasileiro (CESAR, 1999; NETTO, 1996; SERRA, 2000; TAVARES, 2008). Por fim, objetiva-se apresentar um quadro geral dos espaços sócioocupacionais no âmbito público e privado com vistas a desvelar as possibilidades e limites da profissão frente ao atual estágio da acumulação capitalista.

\section{Da emergência do Serviço Social brasileiro ao Movimento de Reconceituação}

Ao iniciar a discussão pela gênese da profissão, objetiva-se capturar os determinantes históricos que influenciaram as mudanças no mercado de trabalho do Serviço Social, desde a sua emergência no Brasil até no atual estágio do capitalismo. Esta incursão histórica que se objetiva realizar é pouco ambiciosa, mas pretende mostrar que o trabalho profissional, como sugere lamamoto (2001), se organiza de acordo com as determinações econômicas e sociopolíticas do processo de acumulação, e orienta-se em função das condições e relações sociais particularizadas em cada período histórico em que se realiza o trabalho.

O pressuposto inicial é o de que o Serviço Social é um tipo de especialização do trabalho inscrito na divisão social e técnica do trabalho 
na sociedade capitalista. Portanto, inscrito no âmbito da produção e reprodução da vida social. Mas, a reprodução das relações sociais ${ }^{1}$ não se limita apenas à reprodução da vida material. Da mesma forma, são reproduzidas as ideias de uma época, em suas representações jurídicas, religiosas, artísticas ou filosóficas, nas quais as transformações decorrentes no modelo de produção são absorvidas na consciência do sujeito. No curso deste processo é produzido e reproduzido o conflito de classes inerente ao processo de produção que representa a luta pelo poder hegemônico de uma das classes em jogo (IAMAMOTO; CARVALHO, 2000).

Para se reproduzir, o capital recria a mola propulsora de permanência desse tipo de organização - a apropriação do trabalho excedente, fonte de mais-valia, e os antagonismos intrínsecos às relações sociais, através da qual se efetiva a produção. Conforme observam lamamoto e Carvalho (2000), neste mesmo processo se reproduzem a contraditória igualdade jurídica de cidadãos "livres" e a desigualdade econômica, fruto do trabalho social ampliado que se confronta com a apropriação privada do trabalho alienado, ao mesmo tempo em que o conteúdo ideológico encobre a verdadeira essência das relações sociais.

Como partícipe do processo que organiza a vida em sociedade, o Serviço Social não fica alheio a essa realidade.

As condições que peculiarizam o exercício profissional são uma concretização da dinâmica das relações sociais vigentes na sociedade, em determinadas conjunturas históricas. Como as classes sociais fundamentais e seus personagens só existem em relação, pela mútua mediação entre elas, a atuação do assistente social é necessariamente polarizada pelos interesses de tais classes, tendendo a ser cooptada por aqueles que têm uma posição dominante (IAMAMOTO; CARVALHO, 2000, p.75).

As bases sócio-históricas da emergência dessa profissão encontram-se atreladas com determinados "problemas sociais" inerentes ao desenvolvimento capitalista, particularmente decorrentes da fase industrial do capital e da consequente expansão urbana das sociedades; da intensificação dos conflitos sociais e da luta de classes, junto à consolidação da burguesia e do proletariado industrial, bem como às relações estabelecidas com o aparelho do Estado (IAMAMOTO; CARVALHO, 2000; NETTO, 2011).

Especificamente no Brasil, o capitalismo industrial e financeiro emerge tardiamente, no início do século XX, intensificando a exploração da força humana de trabalho. Esse aspecto foi fundamental para fomentar

\footnotetext{
1 Por reprodução das relações sociais entende-se "a reprodução da totalidade do processo social; a reprodução de um determinado modo de vida, que envolve o cotidiano da vida em sociedade: o modo de viver, de trabalhar, de forma socialmente determinada, dos indivíduos em sociedade. Envolve a reprodução do modo de produção". (IAMAMOTO; CARVALHO, 2000, p. 71).
} 
o movimento de resistência de tendência anarquista e reformista católica que, apoiado pelos imigrantes propiciou o surgimento dos primeiros sindicatos. Com isso, o movimento dos trabalhadores mostrou-se cada vez mais organizado em termos políticos com significativa presença no cenário nacional.

No Brasil, a "questão social"2 surgiu no final do século XIX, mas permaneceu na ilegalidade por algumas décadas, pois foi formulada como "desordem", criminalizando o sujeito e enfrentada através dos aparelhos repressivos do Estado. Nos anos 1930, a "questão social" passou a ser reconhecida pelo pensamento político sob postulados liberais-democratas como questão política. Neste sentido, Cerqueira Filho (1982) reconhece que a "questão social" surgiu da relação entre capital x trabalho no processo de industrialização, e sob o padrão de substituição de importações, como expressão das contradições que não mais poderiam ser tratadas pela polícia.

Para o seu enfrentamento exigiu-se a intervenção dos poderes públicos, em especial, nas questões trabalhistas e órgãos públicos que pudessem se ocupar dessas questões, mas que no fundo visavam muito mais desmobilizar e despolitizar a classe operária emergente do que eliminar a causa dos conflitos. As soluções passariam, via legislação.

O Estado, na Idade do Monopólio, assume o papel de mediar as relações entre empresariado e a classe trabalhadora, regulamentando juridicamente o mercado de trabalho através das leis de proteção social e trabalhistas específicas, e administrando a organização e prestação dos serviços sociais, como uma nova estratégia de enfrentamento à "questão social".

Não é demais lembrar que o Estado assume uma posição de destaque quando se estuda o Serviço Social, pois, tradicionalmente, é um dos maiores empregadores de assistentes sociais no Brasil. Neste sentido, cabe assinalar a sua importância na reprodução das relações sociais, na sua condição de legislador e de controlador das forças repressivas, como bem sugerem lamamoto \& Carvalho:

Estes dois 'braços' do Estado são mutuamente complementares na tarefa de assegurar o poder e a ordem estabelecida conforme os interesses dominantes. O Estado como centro de exercício de poder político, é a via privilegiada através da qual as diversas frações das classes dominantes, em conjunturas históricas específicas, impõem seus interesses de classe ao conjunto da sociedade, como ilusório interesse geral. (2000, p. 81).

No período do capitalismo monopolista, o Estado burguês procura administrar - de forma contínua, sistemática e estratégica - as expressões

\footnotetext{
2 Por "questão social", apreende-se "o conjunto de problemas políticos, sociais e econômicos que o surgimento da classe operária impôs no curso da constituição da sociedade capitalista. Assim, a 'questão social' está fundamentalmente vinculada ao conflito entre o capital e o trabalho" (CERQUEIRA FILHO, 1982, p. 21).
} 
da "questão social" através da política social. Sua principal função neste estágio é o da preservação e controle da força de trabalho, que se mantém ora ocupada mediante a regulamentação das relações de trabalho, ora lançada no exército industrial de reserva. (NETTO, 2011).

No bojo deste processo, o Serviço Social é requisitado pela classe dominante para intervir nas sequelas da "questão social", como estratégia para assegurar a reprodução das relações sociais com vistas a responder aos interesses do capital. A profissão surgiu com um caráter subordinado, articulado com a burguesia industrial cuja intervenção orientava-se para resgatar a "harmonia social".

O surgimento do Serviço Social brasileiro encontra-se fortemente atrelado às ações da doutrina católica, caracterizado pela parcela feminina de setores abastados da sociedade, configurando um caráter missionário à profissão como meio de fazer justiça e caridade. De acordo com lamamoto e Carvalho (2000), nesse estágio inicial, os centros de formação que embasavam a prática profissional se inspiravam nas encíclicas papais. Portanto, era o pensamento oficial da Igreja Católica reformulado universalmente no bojo de desenvolvimento das relações de produção capitalista que consubstanciava as respostas à "questão social".

Nesse período, a Igreja buscava recuperar áreas de influência e privilégios que havia perdido, frente à crescente secularização da sociedade e das tensões presentes nas relações entre Igreja e Estado. Ela se fortalece defensivamente, e, diretamente orientada pela hierarquia, tenta qualificar "seus quadros intelectuais laicos para uma ação missionária e evangelizadora na sociedade". Na realidade, a Igreja quer tanto negar os princípios do liberalismo quanto o comunismo, que configuram para ela, "um perigo ameaçador à sua posição na sociedade" (IAMAMOTO, 1992, p. 18).

A formação profissional exigia "qualidades naturais" do contingente feminino que deveria apresentar aspectos como a íntegra formação moral, doutrinária, técnica e científica. O corpo docente - de elevado percentual com cursos no exterior, sobretudo na Bélgica e Estados Unidos da América - era formado por religiosos, bacharéis, educadores, médicos sanitaristas, entre outros que deveriam aderir ao movimento católico. (IAMAMOTO; CARVALHO, 2000).

Transcorrido esse estágio inicial, o Estado e o empresariado progressivamente vão atribuindo novas determinações, conferindo legitimidade e institucionalização à profissão, ampliando o mercado de trabalho para o enfrentamento das expressões da "questão social" por meio das políticas sociais. O recrutamento se dá numa base mais ampla e uma parcela significativa dos alunos se insere nas grandes instituições e almeja uma carreira remunerada. Sua função social continuou vinculada ao poder, onde o assistente social é estimulado a concentrar esforços para manter a reprodução das relações sociais que fundamentam a sociedade burguesa. 
O processo de institucionalização da profissão se dinamizou no decorrer do Estado Novo, com claros objetivos de absorver as demandas desencadeadas pela classe trabalhadora urbana, tendo em vista "controlar a reprodução do proletariado urbano e atuar sobre as sequelas mais aberrantes do aumento de sua miséria relativa". (IAMAMOTO; CARVALHO, 2000, p.332). É no contexto de expansão das grandes instituições assistenciais num quadro político "autoritário e paternalista" que o Serviço Social consolida as primeiras experiências de maior expressividade.

De acordo com os autores, isso demonstra que o trabalho do assistente social não é uma demanda da população-alvo dos serviços, isto é, da classe trabalhadora, mas do patronato que paga diretamente por essa força de trabalho especializada. Na maioria das vezes, a demanda é do Estado, que vai definir os serviços sociais prestados aos trabalhadores. Para ter acesso aos serviços, o trabalhador deve passar pelo assistente social, visto que participa da implementação e execução de tais serviços.

Este caráter imperativo não se configura transparente no discurso institucional da profissão. Contraditoriamente, reforça a ideologia altruísta e messiânica (IAMAMOTO, 1992), presente em certas literaturas especializadas $^{3}$. Estas justificam a escolha das profissões, que em suas origens, se constituíram a partir de ações filantrópicas e de benemerência que reconhecem as qualidades pessoais, sobretudo as morais em detrimento às qualidades do saber, ou da ciência.

Esta autorrepresentação do Serviço Social dá origem a um certo caráter missionário do assistente social, desde a sua emergência até os dias atuais; agora não mais revestido pelo discurso da doutrina católica, mas do profissional voltado para servir o povo, o oprimido. Tais argumentos assumem uma importância fundamental para refletir sobre a sua condição de trabalhador assalariado, colocando graves fragilidades ao movimento sindical, ao processo de organização da categoria profissional, e, sobretudo à defesa dos direitos trabalhistas e reivindicações salariais. (IAMAMOTO; CARVALHO, 2000, p. 84-85).

Parece-nos incontestável afirmar que, no Brasil, o assistente social encontra-se inserido numa relação de compra e venda da sua força de trabalho, estabelecendo uma separação entre o trabalho de caráter voluntário e o trabalho que se firma através de uma relação contratual que regula os meios de sobrevivência e reprodução desse tipo de especialização através do salário pago pela sua força de trabalho (IAMAMOTO; CARVALHO, 2000).

\footnotetext{
3 Para Netto, uma das motivações que contribuiu para dissimular o processo efetivo da profissionalização do Serviço Social, trata-se do "eticismo do anticapitalismo romântico que originalmente enforma a sua vontade de intervenção repugna o reconhecimento da mercantilização da sua ação - o signo mais evidente da profissionalização no marco das relações sociais burguesas" (2011, p. 72).
} 
No período desenvolvimentista, dos anos 1940 e 1950, a economia se mostrou em pleno crescimento em consequência de diversos fatores, nos quais se destacam a sensível melhora nas relações internacionais, e também uma política econômica com vistas à consolidação da industrialização.

Tendo em vista criar condições para fazer valer o desenvolvimento econômico, a ideologia desenvolvimentista tornou-se o discurso dominante governamental e propôs o crescimento econômico acelerado, continuado e autossustentado. A questão central era superar a condição transitória do subdesenvolvimento do país. Tal ideologia buscava a expansão econômica, envolvendo a prosperidade, riqueza, grandeza material, soberania, em ambiente de harmonia política e social, e de segurança, esforçando-se para elaborar políticas econômicas com vistas a eliminar a pobreza e a miséria, e situar o Brasil na economia mundial capitalista (IAMAMOTO; CARVALHO, 2000).

Os autores ressaltam que a proposta desenvolvimentista teve o objetivo de integrar o país na dinâmica da sociedade. As razões que justificavam o subdesenvolvimento foram atribuídas ao modelo agroexportador e/ou ao frágil desenvolvimento industrial do país. Por isto, apresentou-se como meta a industrialização de base, devendo ser acelerada e autossustentada, assegurando a liberdade econômica e a própria permanência da expansão.

Neste quadro sociopolítico, o Serviço Social se desenvolveu nos organismos de formação acadêmica, com vistas a "modernizar-se" tanto teoricamente quanto tecnicamente. É significativa a expansão das funções exercidas pelos assistentes sociais em atividades de coordenação e planejamento, expressando uma evolução no status técnico da profissão. Os métodos de Serviço Social de Grupo e de Comunidade assumem relevância, exigindo um redimensionamento de suas funções (IAMAMOTO; CARVALHO, 2000).

Nos diversos campos de trabalho o assistente social assume grande importância, demandando maior esclarecimento de suas funções dentro dos programas de desenvolvimento. O Serviço Social conquista importantes espaços na formulação das políticas e planejamento, sua posição deve redefinir status nas equipes interdisciplinares, demarcando suas funções específicas, mas situando-se numa posição horizontal aos demais profissionais.

Os novos conceitos político-sociais e o desenvolvimento industrial acarretaram maiores compromissos para o Serviço Social, que se empenhou em assumi-los. Segundo lamamoto e Carvalho (2000), a expansão do mercado de trabalho para o assistente social inserido nos diversos campos de trabalho (Previdência, Serviço Social Médico, Reabilitação), solicitou dos mesmos uma maior especialização na graduação, supervisão especializada e cursos específicos de pós-graduação. Tudo isto provocou uma reformulação das escolas de Serviço Social que deveria acontecer no quadro da reforma universitária. 
Nas questões relativas ao mercado de trabalho, registram-se reivindicações para estabelecer uma série de direitos, como por exemplo, a redução da carga horária para o máximo de 30 horas semanais ${ }^{4}$, uma remuneração proporcional ao valor da força de trabalho, com fixação do salário profissional, e um estímulo à organização de entidades sindicais e associações profissionais.

Neste estágio, o mercado de trabalho se mostrou ainda em fase de consolidação e se expandiu de forma residual nos estados brasileiros, apresentando precárias relações de trabalho em sua plena institucionalização. Só para se ter uma ideia dessas frágeis relações trabalhistas, Netto (2004) recorre a Pinto para ressaltar que o baixo valor da força de trabalho do assistente social - ainda nos anos 1980 - tornou-se a expressão da oferta de empregos. Até a década de 1980, este profissional não contava nem mesmo com o piso salarial determinado pela categoria ou pelos órgãos de representação, sendo inclusive, temática tratada no Congresso Brasileiro de Assistentes Sociais (CBAS), em 1982, no Rio de Janeiro.

Este mercado nacional de trabalho redimensionou e se consolidou no período ditatorial, e foi dinamizado não apenas pela reorganização do Estado $^{5}$, mas também pelas grandes empresas monopolistas e empresas estatais. Com efeito, nos anos 1960, o desenvolvimento produtivo levado a cabo no contexto da ditadura militar acirra a produção da "questão social", que se manifestou na pauperização de parcelas significativas da população, no processo de migração para as regiões urbanas e industriais, etc. Destarte, a estratégia do Estado ditatorial para atender algumas das necessidades da classe trabalhadora, se mostrou favorável à ampliação do quadro profissional do Serviço Social.

De fato, este processo incidiu sobre o mercado de trabalho, verificando-se aumento de seus postos de trabalho, onde são apresentadas novas demandas práticas aos assistentes sociais e substantivas alterações nas instituições onde estão inseridos. Estas mudanças exigem um redimensionamento na formação profissional e nos padrões de organização da categoria. Os referenciais teóricos, culturais e ideológicos na autorrepresentação sobre a profissão também sofreram sensíveis modificações. (NETTO, 2004).

Até então, o mercado de trabalho para os assistentes sociais no setor empresarial se mostrava "residual e atípico" e efetivava na esfera privada através das "obras sociais filantrópicas". Estas contavam com o subsídio estatal, mas não eram diretamente organizações oficiais. Foi a partir do

\footnotetext{
${ }^{4}$ Nota-se que um longo período se coloca para a consolidação desta reivindicação, que teve seu desfecho na Lei 12.317, em agosto de 2010. Na realidade, pode-se dizer que ainda está em processo de consolidação, uma vez que muitos empregadores ainda não a cumprem. Por isto, esta conquista ainda demanda a organização dos assistentes sociais na busca da consolidação das 30 horas.

${ }^{5}$ É importante frisar que, neste período, a inserção dos assistentes sociais no âmbito público não se deu apenas no interior das instituições federais. Embora com maior absorção na esfera pública federal, observa-se a presença dos assistentes sociais na esfera estadual e municipal.
} 
crescimento industrial nos anos do "milagre" econômico que o Serviço Social de Empresa se tornou expressivo. Deve-se registrar que este espaço de trabalho não é apenas fruto do crescimento industrial; soma-se a isto o contexto sociopolítico que demarca este desenvolvimento e exige maior "controle da força de trabalho" no âmbito da produção (NETTO, 2004, p.122).

Embora houvesse nesse período um movimento no Serviço Social que indicasse romper com as tradicionais formas de atender às demandas da população, o requisitante de sua intervenção exigia a ação reformista de solucionar e/ou contornar os problemas. Sua função social era a de mediar os conflitos de classe tendo em vista preservar a produtividade do trabalhador, e, consequentemente, o lucro do empresariado.

O Estado ditatorial continuou requisitando, na expressão de Netto (2004), um "executor das políticas sociais", com a função de controlar e adaptar a classe trabalhadora às condições de exploração. Entretanto, são relevantes os aspectos que desencadearam a proposta de renovação do Serviço Social. O contexto econômico da ditadura agravou as expressões da "questão social" que eram "controladas" pelas políticas sociais centralizadas, onde a categoria profissional foi requisitada a ocupar os espaços burocráticos e administrativos no âmbito do Estado e das empresas privadas. Esse Estado "racionalizado" para gerenciar o grande capital influenciou substancialmente as políticas sociais setorizadas para atender à lógica do capital e tornou-se o grande empregador dos assistentes sociais.

Netto (2004) observa que esse processo implicou uma mudança de perfil profissional. Ou seja, em decorrência das exigências do mercado de trabalho, era necessário reformular as bases de formação e expandir quantitativamente os setores educacionais do Serviço Social. Nesse momento há inserção do ensino de Serviço Social na universidade ${ }^{6}$. A expansão do curso provocou o recrutamento de novos docentes, principalmente jovens recém-formados disponíveis para se envolverem e se dedicarem intelectualmente, produzindo uma massa crítica que não existia anteriormente.

Este aspecto, que embora não seja exclusivo, contribuiu significativamente para desencadear o processo de renovação do Serviço Social, que se mostrou expressivo tanto na pesquisa e no ensino, na organização político-corporativa dos assistentes sociais, e também no mercado de trabalho. Conforme lamamoto: "Por meio de sua renovação, o Serviço Social buscava assegurar sua própria contemporaneidade, afigurando-se aquela como o caminho possível para a sua reprodução e expansão: para a sua reconciliação com o tempo presente" (2001, p. 202).

\footnotetext{
${ }^{6}$ Do ponto de vista legal, o reconhecimento do estatuto superior e acadêmico da profissão data do início dos anos 1950. Trata-se, portanto, da incorporação da formação profissional na dinâmica própria da universidade. As escolas que mantinham sua formação "tradicional", com um número reduzido de alunos e um corpo docente que privilegiava os valores morais, transformaram-se em um curto espaço de tempo em complexos universitários (NETTO, 2004).
} 
O processo de renovação ganhou um movimento mais intenso quando se percebeu a maturação de segmentos da categoria profissional articulada com outros atores sociais nas equipes multiprofissionais: movimentos sociais e políticos, outras esferas administrativas e políticas do Estado. Refere-se também, ao desligamento de segmentos da Igreja Católica frente ao tradicionalismo da profissão; a manifestação de católicos progressistas afinados à categoria profissional; o movimento estudantil e seu ingresso nos cursos de Serviço Social, particularmente orientado pelos movimentos da esquerda católica, que mais tarde ingressaram nos quadros docentes do Serviço Social; e a contribuição do referencial das ciências sociais desse período conectado por dimensões críticas e nacional-populares. (NETTO, 2004, p.139-140).

Por isso, Netto (2004) avalia que no pós-64, o fenômeno mais importante para o Serviço Social foi o seu processo de renovação, tendo em vista os inúmeros desdobramentos notados na formação e exercício profissional, e também na organização política da categoria profissional.

O movimento de Reconceituação do Serviço Social teve sua emergência em meados dos anos 1960, e é preciso reconhecer que se trata de um fenômeno tipicamente dos países latino-americanos. Tem se caracterizado pela contestação ao tradicionalismo profissional, e "implicou um questionamento global da profissão: de seus fundamentos ídeo-teóricos, de suas raízes sociopolíticas, da direção social da prática profissional e de seus modus operandi". (IAMAMOTO, 2001, p. 205-206).

Para Netto (2004) este movimento não foi homogêneo e abrigou várias tendências ${ }^{7}$ em seu interior, abrindo-se para o pluralismo na profissão. A proposta central de "intenção de ruptura" com o conservadorismo profissional se fundou na investigação da profissão a partir de referências marxistas de análise dos fenômenos sociais e o emprego de novas metodologias de ação, que levassem em conta a totalidade do social. A realização de práticas a partir de uma perspectiva dialético-marxista apresentou, na primeira aproximação, uma nítida influência do pensamento althusseriano. Em um segundo momento, há uma aproximação do marxismo dentro da academia, obedecendo às exigências intelectuais rigorosas, tanto para a crítica ao tradicionalismo da profissão (Método $\mathrm{BH}$ ), quanto para a análise histórica da mesma (lamamoto). Em um terceiro momento, o recurso ao marxismo possibilitou produções que analisam a atualidade da profissão (problemática da formação, a intervenção, os campos de prática, etc), com destaque para os estudos de Sposati, Yasbek e Mota.

Entretanto, Netto (2004) observa que o Método BH e as produções de Marilda lamamoto é que podem ser considerados marcos históricos na

\footnotetext{
7 Não se pretende desenvolver um denso exame sobre o processo de renovação do Serviço Social no Brasil, visto os limites deste estudo. Não obstante, cabe informar que os estudos de Netto (2004) indicam três principais vertentes assumidas pela categoria profissional - "modernização conservadora", "reatualização do conservadorismo" e "intenção de ruptura".
} 
consolidação da vertente intenção de ruptura. O primeiro por ser uma elaboração cuidadosa de uma proposta alternativa ao Serviço Social tradicional e fundante da vertente e a segunda por ser um sinalizador da maturidade intelectual do processo, além de exercer ponderável influência no meio profissional.

A renovação profissional construiu um acúmulo no interior do qual é possível reconhecer [...] pela primeira vez na história do Serviço Social nestas plagas - as tendências fundamentais que mobilizam as classes e os grupos sociais brasileiros no enfrentamento dos problemas da economia, da cultura e da história. (NETTO, 2004, p. 308).

O Serviço Social na contemporaneidade é produto desse processo e se mostra inovador, à medida que a categoria profissional - historicamente atrelada aos interesses das classes dominantes - aponta para a construção de um projeto que absorve expressões e interesses da classe trabalhadora, presente na arena política na luta pela redemocratização no Brasil. É neste contexto que se inicia um novo projeto ético-político profissional consolidado nos anos de 1990, mas em permanente construção, e materializado no Código de Ética Profissional de 1993 que caminha na contramão das tendências sociais, políticas, econômicas e ideológicas em curso no Brasil e no mundo.

\section{Transformações societárias e Serviço Social: panorama dos diferentes espaços sócio-ocupacionais}

Pensar o Serviço Social no contexto das "transformações societárias" (NETTO, 1996) requer uma apropriação dos elementos que conformam tais mudanças. Assim, deve-se levar em conta o processo de mudanças no modelo de produção capitalista, o conflito entre as classes em disputa e o papel do Estado como garantidor da reprodução social. Mas, também, reconhecer a própria atividade do Serviço Social no contexto destas mudanças.

Segundo Mota e Amaral (2006), a reestruturação do processo de produção se apoia nas novas tecnologias de última geração, adaptando o trabalho ao uso de sistemas altamente computadorizados. Isto provoca, de imediato, uma drástica redução da força humana de trabalho, num momento em que se difundem propostas ideológicas de fragilização do movimento operário e sindical que se manifestava, até então, como combativa ao sistema capitalista, produzindo uma nova situação às negociações entre as classes em disputa.

Tais mudanças têm sido consideradas como alternativa ao modelo de produção fordista, e são caracterizadas pela flexibilização nos processos e nas condições de trabalho, modificando significativamente a composição 
da classe trabalhadora ou o mercado de trabalho, por meio do desemprego, terceirização, precarização do trabalho e dos vínculos formais de trabalho (MOTA; AMARAL, 2006).

A crise contemporânea tem provocado, também, mudanças na esfera do Estado, encaminhadas pelo acordo realizado no Consenso de Washington, que exige políticas de ajustes de base neoliberal. A crise fiscal do Estado no contexto da crise econômica tem produzido uma redução nos padrões de financiamento dos serviços públicos. Os preceitos neoliberais propõem o enxugamento dos gastos governamentais.

Não por acaso, os gastos sociais foram os mais afetados, repercutindo diretamente no campo das políticas sociais cada vez mais focalizadas e setorializadas e, por conseguinte, mais precarizadas. É como observa lamamoto, o enxugamento do Estado remete a uma só direção: "incide sobre a esfera de prestação de serviços sociais públicos que materializam direitos sociais dos cidadãos, de interesse da coletividade". Inversamente, tem-se uma expansão da proteção do Estado para o capital, representado pela figura dos grandes oligopólios. (2001, p. 36). Tudo isso provoca alterações no "conjunto das práticas sociais, onde se insere a experiência profissional do Serviço Social". (MOTA; AMARAL, 2006, p. 24).

De fato, ao analisarem trabalhos publicados nos três últimos Congressos Brasileiros de Assistentes Sociais (CBAS), Alencar e Granemann (2009) avaliam que a problematização das experiências profissionais mostra expressivas mudanças processadas nas instituições empregadoras dos assistentes sociais no que se refere à orientação e natureza das políticas sociais.

No contexto social brasileiro, sob o discurso da crise econômica e da escassez de recursos, tendem a ser estruturadas ações que ferem a condição de direito das políticas sociais de caráter universalista. As orientações da política social em geral e da assistência social em particular fundamentam-se, para a força de trabalho que as executam, com fortes traços e tendências de precarização, focalização e descentralização, e, nesse quadro, as atividades filantrópicas e voluntárias e os novos 'entes' do estado brasileiro tornam-se parceiros importantes e, supostamente, ajudam a tecer a "gestão da pobreza". Somese ainda a numerosa gama de variantes da privatização da seguridade e das políticas sociais e de assistência que passam a ser alocadas no mercado, quando passíveis de lucro, e/ou na sociedade civil, pela transferência de partes do fundo público para a intervenção privada sob a 'questão social'. (ALENCAR; GRANEMANN, 2009, p. 166).

Entretanto, cabe assinalar que as características que estruturam a sociedade brasileira e sua forma de inserção no capitalismo contemporâneo demonstram que a necessidade/utilidade social desta profissão "não tende a se contrair", garantindo espaços sócio-ocupacionais aos assistentes sociais. Numa realidade bastante adversa em que se instauram distintas hegemonias políticas, realizando diferentes projetos sociais no contexto nacional, isto 
irá demandar diferentes "perspectivas e estratégias de ação profissional". (NETTO, 1996, p.115).

Diferente dos confrontos que se travaram no passado recente, Netto (1996) avalia que o embate mais imediato se processa pelas demandas do mercado de trabalho, mas que ainda não apresentam em sua estrutura as inflexões suficientemente elucidadas. Em razão das "transformações societárias" e suas repercussões no Brasil, o mercado de trabalho está sofrendo profundas metamorfoses, seja pela redução das demandas de atividades antes significativas, seja pelo surgimento de novas atividades.

De acordo com o autor supramencionado, algumas indicações são indiscutíveis. A democratização da sociedade e a consagração dos direitos sociais ampliaram espaços para a intervenção profissional; as transformações nas instituições estatais no marco da Constituição Federal de 1988 atuaram na mesma direção; e, em consequência do modelo econômico que se gestou na ditadura militar, a demanda de assistentes sociais pela esfera privada ampliou significativamente.

Para Netto (1996), a particularidade das transformações em curso na realidade brasileira pode configurar uma sobreposição no campo das atividades profissionais, das demandas "tradicionais" e das "novas" configurando um campo de ação bastante heterogêneo e complexo, exigindo um profissional criativo e eficaz no trato de suas ações.

O autor chama a atenção para a ausência de estudos e pesquisas sobre o mercado de trabalho, mas aponta para as seguintes questões: uma maior segmentação do trabalho profissional exigindo uma determinada especialização dos profissionais; e a gradual diferenciação das condições de trabalho no setor estatal e no setor privado, sendo que este último apresenta um esquema de controle e aferição mais rigoroso do desempenho profissional.

É a respeito desses espaços sócio-ocupacionais que se pretende abordar. Comecemos pela esfera pública. Inicialmente, é importante ressaltar que estudos e pesquisas (SILVA, 1999 apud IAMAMOTO, 2001; SERRA, 2000; CFESS/CRESS, 2005; TAVARES, 2008) vêm sustentando a tendência do Serviço Social se manter atrelado ao Estado enquanto requisitante do seu trabalho ${ }^{8}$. Em outras palavras, o Serviço Social legitima-se até os dias atuais como profissão institucionalizada, com maior absorção na esfera pública. Sustentam, também, que esse mercado de trabalho sofre os efeitos deletérios das transformações em curso na sociedade brasileira, através da precarização das relações e condições de trabalho na esfera pública e privada.

\footnotetext{
${ }^{8}$ Os dados da pesquisa "Assistentes sociais no Brasil: elementos para estudo do perfil profissional" revelam que os assistentes sociais continuam sendo trabalhadores assalariados, com nítida inserção nos organismos estatais, com maior incidência para a área da saúde e da assistência social: $78,16 \%$ atuam em instituições estatais, sendo que 40,97\% atuam na esfera municipal, $24 \%$ na esfera do Estado e 13,19\% na esfera federal (CFESS/CRESS, 2005).
} 
No que se refere aos espaços de trabalho, as políticas sociais que compõem a Seguridade Social, a partir da Constituição Federal de 1988, constituem espaços privilegiados de trabalho para o Serviço Social. Na esfera municipal, abriram-se novas possibilidades de intervenção motivadas pela municipalização das políticas públicas. Para lamamoto (2001), a implementação dos conselhos municipais, a capacitação de conselheiros, a elaboração e gerenciamento de projetos sociais, e a organização e mobilização popular em práticas de orçamento participativo, são algumas das fontes de diversificação de demandas para o trabalho do assistente social.

Nas instâncias públicas de controle democrático, o trabalho do assistente social tem sido analisado por Bravo (2009) a partir de uma dupla inserção: uma se destaca no campo político de ação quando se reconhece a participação dos assistentes sociais enquanto conselheiros; a outra inserção se caracteriza como um novo espaço sócio-ocupacional que apresenta a atividade de assessoria aos conselhos ou dos segmentos presentes nesta instância (usuários, trabalhadores e poder público).

Para Bravo (2009), a efetivação da participação social e o controle democrático nas políticas públicas no atual quadro sócio-histórico enfrentam grandes desafios, visto que o ganho ideológico neoliberal no Brasil nas diferentes esferas governamentais tem produzido efeitos nefastos ao fortalecimento das instâncias democráticas, da ampliação da esfera pública e da garantia de direitos sociais. Neste campo de ação profissional, Bravo destaca:

Os profissionais adeptos do projeto ético-político da profissão precisam qualificar suas ações a fim de contribuírem para a ampliação de uma cultura política crítica e democrática necessária ao efetivo controle democrático dos sujeitos coletivos que buscam na arena política - enquanto interlocutores e representantes dos interesses da maioria da população - defender a garantia de direitos sociais, num cenário de regressão dos mesmos e de destruição das conquistas históricas dos trabalhadores. (2009, p. 10).

O processo de implantação e implementação do Sistema Único de Assistência Social (SUAS) também contribui para a ampliação dos espaços de trabalho na esfera municipal. O impacto do SUAS no mercado de trabalho ocorre com a criação dos Centros de Referências de Assistência Social (CRAS) e os Centros de Referências Especializados de Assistência Social (CREAS) que absorvem, em cada um deles pelo menos um assistente

\footnotetext{
${ }^{8}$ Os dados da pesquisa "Assistentes sociais no Brasil: elementos para estudo do perfil profissional" revelam que os assistentes sociais continuam sendo trabalhadores assalariados, com nítida inserção nos organismos estatais, com maior incidência para a área da saúde e da assistência social: $78,16 \%$ atuam em instituições estatais, sendo que 40,97\% atuam na esfera municipal, $24 \%$ na esfera do Estado e 13,19\% na esfera federal (CFESS/CRESS, 2005).
} 
social ${ }^{9}$. Com a municipalização das ações do SUS e agora do SUAS, as prefeituras podem estar concentrando maior número de assistentes sociais no quadro profissional.

Este dado embora se mostre aparentemente favorável, visto que representa uma expansão no mercado de trabalho, tem sido analisado criticamente, uma vez que se identifica a ocorrência da precarização e flexibilização das relações e condições de trabalho na esfera municipal. (TAVARES, 2008).

Ao investigar as relações e condições de trabalho do assistente social, a pesquisa de Tavares $(2008)^{10}$ revelou que a esfera pública municipal, especialmente no âmbito da política de assistência social, apresenta maior precarização da inserção deste profissional. Além da baixa remuneração, apresentou formas de vínculo empregatício através de contratação temporária e flexível, isenta de direitos sociais, e da necessidade de se ter um ou mais empregos para recuperar os níveis salariais. É importante destacar que o tipo de contratação flexível pode interferir diretamente na permanência deste profissional na instituição empregadora, o que gera grande rotatividade da força de trabalho.

$\mathrm{Na}$ literatura sobre a questão argumenta-se que a tendência às precárias condições de trabalho do assistente social no mercado deve ser criteriosamente analisada, na medida em que pode interferir diretamente no nível da qualidade de inserção profissional e na qualificação profissional (SERRA, 2000; IAMAMOTO, 2001; TAVARES, 2008).

As autarquias e fundações sob administração estatal estão se constituindo em instituições autônomas ou executivas, e são administradas através de um contrato de gestão. Trata-se de um instrumento que tem como objetivo estabelecer metas a serem cumpridas, recursos necessários para execução do trabalho e os critérios instrumentais para avaliar prazo. (IAMAMOTO, 2001).

A "gestão social pública" ou "gerência pública" abre espaço para um conjunto de especializações profissionais (assistentes sociais, pedagogos, sociólogos, etc.). E para cumprir o exercício de funções requeridas no campo da gestão de políticas sociais públicas, exigem-se níveis de aperfeiçoamento na formação profissional e não somente o diploma. Diante da competitividade imposta pelo mercado de trabalho, torna-se imprescindível a qualificação profissional que possibilite ao assistente social concorrer em igualdade de condições com outros profissionais. (IAMAMOTO, 2001).

$\mathrm{Na}$ esfera privada, surgem novas configurações do Serviço Social nas empresas, nas fundações empresariais, na área de Recursos Humanos e nas ONGs. No caso das médias e grandes empresas, a demanda é de pro-

\footnotetext{
${ }_{9}$ O número de assistentes sociais nos CRAS e CREAS dependerá do porte do município, e do número de famílias atendidas, conforme definição da NOB/SUAS.

10 Tal afirmação está ancorada no estudo realizado no curso de mestrado em Serviço Social no PPGSS/UERJ que atribuiu ênfase ao mercado de trabalho do Serviço Social no contexto da reestruturação produtiva. A pesquisa foi realizada entre os meses de julho e setembro de 2007, no município de Volta Redonda/RJ e abrangeu a esfera pública e privada.
} 
fissionais para mediar as relações entre o empregador e a classe trabalhadora, e para contribuir com as novas formas de gestão da força de trabalho, na administração de "benefícios sociais" e, também, no encaminhamento de novos métodos organizacionais de trabalho (Círculo de Controle de Qualidade - CCQ, Controle de Qualidade Total - TQC).

Cesar (1999) destaca que as novas estratégias de gestão e políticas de recursos humanos nas empresas, criam condições específicas para que o trabalhador assuma o seu novo papel através de Programas de Qualidade Total. Tais princípios se pautam em um modelo que objetiva reorganizar o trabalhador coletivo dentro dos parâmetros enunciados pelas novas exigências da racionalidade produtiva e suas necessidades para controle e eficiência.

A participação e o comprometimento surgem como vetores essenciais das novas modalidades de gerenciamento, e visam reduzir os níveis de conflito entre capital e trabalho. As políticas legitimadas pelas empresas estão relacionadas aos planos de cargos e salários, ao sistema de incentivos, benefícios extrassalariais, entre outros. (CESAR, 1999). As políticas de recursos humanos se beneficiam do consenso ideológico intensificando o comportamento do trabalhador às exigências do processo de produção por meio de uma ação promocional e pedagógica.

Tudo isso confere uma nova configuração ao trabalho do assistente social nas empresas, e ao mesmo tempo, altera significativamente as condições de trabalho na qual este exercício se concretiza. A autora observa que as estratégias vão mediar as relações de trabalho, com o objetivo de sustentar a estabilidade e o desempenho do trabalhador através do controle dentro e fora da fábrica.

A intervenção profissional fundamentar-se-á na interlocução da ação social da empresa privilegiando algumas expressões que circulam na sociedade burguesa, como "competitividade" numa parceria entre trabaIhador e empresa. Os sentidos pedagógico, moralizante e disciplinador se ajustam às novas técnicas e discursos gerenciais, que divulgam a participação e colaboração. Logo, o trabalho profissional nas empresas se pauta pelos novos conteúdos de controle nos processos e relações de trabalho.

Ainda no contexto das empresas, Netto (1996) coloca uma tendência à "terceirização" do trabalho dos assistentes sociais, com objetivos de restringir (ou até mesmo extinguir!) o quadro de profissionais com vínculos empregatícios com as empresas, estimulando o trabalho autônomo, e em vista disto, as "fantasias" em torno de um novo estatuto liberal para os assistentes sociais envolvidos ${ }^{11}$.

\footnotetext{
11 A título de exemplo, ressalta-se que uma empresa do setor privado, instalada no município de Volta Redonda/RJ, manteve um quadro de profissionais do Serviço Social até setembro de 2003, momento em que ocorreu a demissão de todo o quadro profissional. Logo após a extinção do Serviço Social, esta empresa passou a contratar assistentes sociais para desenvolverem projetos temporários e/ou tarefas pré-definidas.
} 
A "filantropia empresarial" é um setor em crescimento, e representa um novo modelo de ação social, na qual as empresas "cidadãs" investem no campo social através de projetos comunitários compreendidos como de interesse público. Esse setor constitui também, espaço de trabalho para os assistentes sociais. Ao analisar esse setor, lamamoto (2001) observa que a lógica que move os projetos e programas sociais não é de interesse público, e sim privado.

As exigências para ingressar na esfera empresarial não se limitam ao campo de conhecimentos: é necessário que se tenham qualidades e habilidades pessoais, tais como experiência, criatividade, capacidade para negociar, fluência verbal, o domínio não só da língua inglesa, como o espanhol, informática, entre outros. (IAMAMOTO, 2001).

No âmbito das instituições sem fins lucrativos, cabe ressaltar que a "contrarreforma do Estado" propõe novas relações entre Estado e sociedade civil, onde o governo se desresponsabiliza diretamente pelo desenvolvimento social e econômico e passa a promover e regular esse desenvolvimento, transferindo as responsabilidades para o setor privado, as ações que possam ser gerenciadas pelo mercado. Para lamamoto (2001), tais aspectos encontram-se traduzidos na privatização das empresas estatais e na "publicização" dos serviços de saúde, educação e cultura, possibilitando um abandono do Estado no papel de executor destes serviços ${ }^{12}$.

Nesta perspectiva, o Estado se preocupa em fortalecer e regulamentar o chamado "terceiro setor" para gerenciar e executar as políticas sociais, refletindo nas condições de trabalho e mercado de trabalho especializado. O "terceiro setor" se coloca como um dos atores no debate e nas práticas tidas como definidoras das novas relações entre Estado e sociedade civil. No Brasil, discute-se amplamente o papel que deve ser representado pelo "terceiro setor", no âmbito das políticas públicas e nas transformações do Estado. (LANDIM, 1999).

Netto (1996) afirma que o discurso ideológico que privilegia as iniciativas da sociedade civil através das chamadas "parcerias" - escamoteando a desresponsabilização do Estado no trato com a problemática social - tem se configurado como entrave à efetividade da cidadania. Nesse mesmo processo em que os direitos sociais promulgados constitucionalmente se flexibilizam e se vêem desregulamentados, a cidadania torna-se a palavrachave para garantir distintas reivindicações.

“Em nome das iniciativas da sociedade civil e da cidadania, [...] a cultura antiestatista tem levado segmentos profissionais a valorizar, quando não a priorizar, as chamadas organizações não-governamentais (as ONGs) como espaço profissional" (NETTO, 1996, p.122).

\footnotetext{
12 Neste sentido, a "publicização" refere-se à descentralização, para o setor público não estatal, da execução de serviços que não comprometam o Estado, mas que por ele são subsidiados. xemplos: a educação, a saúde, a cultura e a pesquisa científica. Cf. lamamoto (2001, p.121).
} 
Em que pesem as avaliações positivas e significativas das ONGs, salienta-se que estes espaços profissionais devem ser vistos com certa reserva, uma vez que a maioria deles não se configura como um canal expressivo e estável de mercado de trabalho. A absorção de mão-de-obra nas ONGs tem se mostrado precária, com vínculos trabalhistas parciais. Ao pleitear as ONGs como "saída profissional", deve-se atentar para os riscos do "pluriemprego", onde os profissionais são coagidos a experimentar vários vínculos empregatícios (NETTO, 1966).

O investimento nesta proposta representa tão somente uma estratégia de reestruturação do capital que visa uma transformação do padrão de resposta às sequelas da "questão social". Para Montaño (2003), esta estratégia envolve a perda dos direitos sociais inscritos nas políticas sociais; a precarização e focalização das mesmas, e a refilantropização da "questão social". Neste debate, há uma crença otimista no poder democratizador presente na proposta do "terceiro setor", e um pessimismo em relação ao Estado, desconsiderando ser este um espaço de lutas.

Nesse campo, o tipo de contratação de trabalho se efetiva de acordo com projetos temporários ou tarefas anteriormente definidas, submetendo o corpo técnico "à precarização das relações de trabalho e à restrição de direitos sociais e trabalhistas". Esta diferenciação interna em termos contratuais entre profissionais concursados e contratados exercendo tarefas semelhantes traz graves consequências para o movimento sindical, afetando também o assistente social. (IAMAMOTO, 2001, p.126).

Na avaliação de Netto (1996), a questão central que emerge das alterações imediatas no mercado de trabalho não se encontra em manter os espaços de trabalho, nem mesmo no atendimento ou não das suas demandas. A questão do espaço profissional não pode ser avaliada a partir de uma perspectiva corporativa, mas sim de novas competências. Para responder às demandas do mercado, a questão se funda em como respondê-las, se levarmos em conta que a própria determinação das demandas do mercado de trabalho é problemática.

Do ponto de vista neoconservador, que pode reunir de conservadores históricos a pós-modernos, identifica-se empiricamente que as demandas do mercado devem ser os determinantes da formação profissional, ou seja, esta deveria responder ao mercado de trabalho. $\mathrm{E}$, do ponto de vista da direção social estratégica pensada no início da década de 1990, não cabe apenas se contentar com a sinalização do mercado de trabalho. Esta deve associar o mercado de trabalho às tendências societárias mais gerais - o que requer um denso investimento na pesquisa da realidade e a apreensão de categorias e procedimentos da teoria social clássica - e aos objetivos e valores consagrados no projeto ético-político profissional. Desta forma, a resposta às demandas do mercado deve abranger prioridades e alternativas. (NETTO, 1996). 
Enfim, o autor chama a atenção para o confronto existente entre dois "paradigmas" de profissional: o técnico altamente treinado para operar instrumentalmente sobre as demandas do mercado de trabalho apenas a partir do que está posto ou o intelectual qualificado que vai operar e intervir sobre aquelas demandas, a partir de um embasamento teórico-crítico, identificando a significação, os limites e as alternativas da ação focalizada. São estes os traços mais gerais sobre a reestruturação do mercado nacional de trabalho dos assistentes sociais nos marcos do capitalismo contemporâneo.

\section{Considerações Finais}

Ao traçar algumas considerações sobre o panorama do mercado de trabalho para o assistente social nos diversos espaços sócio-ocupacionais na contemporaneidade, este texto priorizou uma análise que buscou os fundamentos do Serviço Social para compreender a efetividade histórica que permite sua existência nas diferentes conjunturas históricas. É neste sentido que se justifica a abordagem histórica como um recurso imprescindível para os debates atuais da profissão e da busca das possíveis respostas aos seus questionamentos em relação às mudanças projetadas para este novo milênio.

Se o percurso histórico nos mostra que o Serviço Social se inscreve na sociedade brasileira como um trabalhador assalariado, este profissional especializado sofre as radicais alterações que se processam na esfera do trabalho, mas também sofre um grande impacto na esfera de atendimento à população que demanda o seu trabalho. É, como diz lamamoto (2001), a redução e/ou eliminação de postos de trabalho e a ampliação do mercado informal de trabalho estão presentes no cotidiano do exercício profissional do assistente social, pois afetam tanto as relações e condições de trabalho, quanto o cotidiano da população que demanda o seu trabalho.

O panorama não se mostra favorável, na medida em que a revisão da literatura indicou, nos diversos campos de atuação do assistente social, as precárias condições e relações de trabalho, intensificando a exploração da força humana de trabalho. Mas, se por um lado o assistente social sofre diretamente as consequências nefastas deste processo, por outro lado, o Serviço Social brasileiro vem se destacando, sobretudo no continente latinoamericano, em relação aos avanços teórico-metodológicos de tradição histórico-crítica conquistados e preservados até os dias atuais. Ainda se pode afirmar que o embasamento teórico-metodológico - que orienta o projeto ético-político e, portanto, o trabalho profissional - permanece hegemônico na profissão. Isto é significativo, pois abre possibilidades para decifrar as questões que perpassam o seu cotidiano de trabalho, identificando os desafios que devem ser enfrentados coletivamente. 


\section{Revista all pavtg}

\} REPERCUSSÕES DAS METAMORFOSES NO MERCADO - TAVARES, M. A. S. \}

Em suma: este texto pretendeu expressar a tendência mais geral do mercado de trabalho do Serviço Social no Brasil. As modificações que se processam na esfera pública e privada indicam a importância da formação e da qualificação profissional para responder com competência crítica e comprometimento ético-político às necessidades e demandas sociais, considerando, evidentemente, os limites e possibilidades desse tipo de especialização do trabalho. 


\section{Referências}

ALENCAR, M.M.T.; GRANEMANN, S. Ofensiva do capital e novas determinações do trabalho profissional. Katálysis, Florianópolis, v. 12, n.2, jul./ dez. de 2009, p. 161-169.

BRAVO, M.I.S. O trabalho do assistente social nas instâncias públicas de controle democrático In: CFESS/ABEPSS. Serviço Social: direitos sociais e competências profissionais. Brasília/DF: CFESS/ABEPSS, 2009. Disponível em: <http://xa.yimg.com/kq/groups/15556754/2140373682/name/2__Texto-base_II.pdf>.Acesso em: 12 ago. 2011.

CFESS/CRESS. Assistentes sociais no Brasil: elementos para o estudo do perfil profissional. Brasília, CFESS/CRESS/UFAL, 2005.

CERQUEIRA FILHO, G. A questão social no Brasil: crítica do discurso político. Rio de Janeiro: Civilização Brasileira, 1982.

CESAR, M.J. A experiência do Serviço Social nas empresas. In: CFESS/ABEPSS. Capacitação em serviço social e política social. Brasília: CFESS/ABEPSS/ CEAD-UnB, 1999, p.167-180.

IAMAMOTO, M.V. Renovação e conservadorismo no serviço social: ensaios críticos. São Paulo: Cortez, 1992.

2001.

. O serviço social na contemporaneidade. 4a.ed., São Paulo: Cortez,

. CARVALHO, R.. Relações sociais e serviço social no Brasil: um esboço de uma interpretação histórico-metodológica. 13a. ed., São Paulo: Cortez, 2000.

LANDIM, L.. Notas em torno do terceiro setor e outras expressões estratégicas. O social em questão, n. 4, ano 3, PUC, Rio de Janeiro, 1999, p.6198.

MONTAÑO, C. Terceiro setor e questão social: crítica ao padrão emergente de intervenção social, 2a. ed., São Paulo: Cortez, 2003.

MOTA, A.E.; AMARAL, A.S. Reestruturação do capital, fragmentação do trabalho e Serviço Social. In: MOTA, A.E. (Org). A nova fábrica de consensos: ensaios sobre a reestruturação empresarial, o trabalho e as demandas ao Serviço Social. 3a. ed., São Paulo: Cortez, 2006.

NETTO, J.P. Transformações societárias e Serviço Social: notas para uma análise prospectiva da profissão no Brasil. Serviço social \& sociedade, n. 50, Ano XVII, São Paulo: Cortez, 1996, p.87-132.

A construção do projeto ético-político contemporâneo. In CFESS/ ABEPSS. Capacitação em serviço social e política social. Brasília: CFESS/ ABEPSS/CEAD-UnB, 1999, p.92-109. 


\section{Revista all pavtg}

\} REPERCUSSÕES DAS METAMORFOSES NO MERCADO - TAVARES, M. A. S. \}

NETTO, J.P. Ditadura e serviço social: uma análise do serviço social no Brasil pós-64. 7a. ed., São Paulo: Cortez, 2004. 2011.

. Capitalismo monopolista e serviço social. 8a. ed., São Paulo: Cortez,

SERRA, R. Crise da materialidade no serviço social. São Paulo: Cortez, 2000.

TAVARES, M.A.S.. O Serviço social no contexto da reestruturação produtiva: o mercado profissional de trabalho no município de Volta Redonda-RJ. Dissertação (Mestrado) - Programa de Pós-Graduação em Serviço Social. Universidade do Estado do Rio de Janeiro. Rio de Janeiro: (PPGSS/UERJ), 2008, $201 f$.

Recebido em 14 de setembro de 2012.

Aprovado para publicação em 31 de outubro de 2012. 